\title{
Fixation of extra-articular distal humerus fractures with a single posterolateral plate
}

\author{
Naidoo $T^{1}$, Govender $\mathrm{S}^{2}$ \\ 1 MBChB, FCOrtho, HDip(Ortho), BMed Sci(Hons); Orthopaedic surgeon, Department of Orthopaedics, Northdale Hospital, Nelson R Mandela School of Medicine, \\ University of KwaZulu-Natal, South Africa \\ ${ }^{2}$ MBBS, MD, FRCS, FC(Orth)PR; Professor and orthopaedic surgeon, Spinal Unit, King Dinuzulu Hospital, Durban, South Africa
}

Corresponding author: Dr Thivani Naidoo, Private bag X9006, Pietermaritzburg, 3200; tel 033 387 9000; email: thivaninaidoo@gmail.com

\begin{abstract}
Background: Our study aimed to establish that use of a single posterolateral plate for the open reduction and internal fixation of extraarticular metaphyseal humerus fractures resulted in consistent fracture healing, good functional outcomes and low complication rates.

Methods: A retrospective study was conducted at the Department of Orthopaedics, Northdale Hospital, Pietermaritzburg. A review of case X-rays and patient files from 1 January 2015 to 30 November 2017 of all patients who underwent operative intervention for extra-articular metaphyseal distal humeral fractures was undertaken. Standardised radiographs, functional assessment criteria (Quick Disabilities of the Arm, Shoulder and Hand Score - QuickDASH Score) and post-operative complications recorded in the patients' charts were analysed.

Results: Fifteen patients were included in the study. Ten male patients and five female patient's charts were analysed. The mean age of the participants was 33.13 years. All 15 patients showed adequate fracture healing on X-ray involving three or four cortices of the fracture site. There was no post-operative loss of fracture fixation. The mean humeral metaphyseal-diaphyseal angle was $84^{\circ}$, mean humeral-ulnar angle was $18^{\circ}$, mean shaft condylar angle was $40.4^{\circ}$, and the mean percentage of the capitellum anterior to the anterior humeral line was 49.3 per cent. The mean duration of surgery was 95.4 minutes. The mean QuickDASH score was 19.39.

Conclusion: The use of a single posterolateral plating system for the fixation of extra-articular distal humeral fractures provides a viable alternative to dual plating. This method of fixation provided adequate stability of fracture fixation, good functional outcomes, low complication rates, shorter surgical times and less soft tissue dissection. This study supports current published evidence in this regard.
\end{abstract}

Level of evidence: Level 4

Key words: distal, humerus, fracture, extra-articular, posterolateral plate

Citation: Naidoo T, Govender S. Fixation of extra-articular distal humerus fractures with a single posterolateral plate. SA Orthop J 2018;17(3):35-40 http://dx.doi.org/10.17159/2309-8309/2018/v17n3a4

Editor: Prof LC Marais, University of KwaZulu-Natal, Durban

Received: February 2018

Accepted: May 2018

Published: August 2018

Copyright: (c) 2018 Naidoo T. This is an open-access article distributed under the terms of the Creative Commons Attribution Licence, which permits unrestricted use, distribution and reproduction in any medium, provided the original author and source are credited.

Funding: This study required no funding.

Conflict of interest: The authors declare they have no conflicts of interest that are directly or indirectly related to the research. 


\section{Background}

South Africa has a unique socio-economic background that presents significant challenges for healthcare provision. There is a high burden of injuries related to violence and road traffic accidents. ${ }^{1}$ Eastwood noted that fractures of the distal humerus account for $2 \%$ of all fractures in the body. ${ }^{2}$ Ten per cent of distal humerus fractures in adults are extra-articular supracondylar humerus fractures. ${ }^{3}$

The elbow joint has a highly functional articulation, required for activities of daily living. It is a constrained hinge joint, allowing the ulna to rotate around the axis of the trochlea. ${ }^{4}$ It forms part of a single synovial joint that encompasses three separate articulations: ulnar-humeral, proximal radio-ulnar and radio-capitellar. ${ }^{5}$ Elbow joint articulations include flexion-extension, pronationsupination and limited varus-valgus. Anatomical restoration of these articulations should allow loads of 0.3 to 0.5 times the body weight. The distal humerus is considered a two-column structure supporting the articular segment. The distal portion of the lateral column (capitellum) projects anteriorly approximately $35^{\circ}$ to $45^{\circ}$. The medial column terminates at the medial epicondyle which does not curve anteriorly. The lateral column shares $60 \%$ of the load and the medial column $40 \%$. Pseudoarthrosis of the distal humerus usually occurs in the region of the metaphyseal and supracondylar level of radial columns due to varus stresses. ${ }^{6-8}$

Involvement of the radial nerve in these injuries plays a significant role in complications for both operative and nonoperative management. The injury may arise following the initial trauma or during surgical intervention. ${ }^{9,10}$ The radial nerve courses in a caudal and lateral orientation around the posterior humerus in the spiral groove. ${ }^{11}$ The path of the radial nerve distally increases the risk of injury for this subset of fractures. ${ }^{12}$

Treatment options for these fractures remain a challenge. Functional bracing versus operative fixation are the two options available. Jawa et al. found that operative treatment achieves more predictable alignment and potentially earlier return of function than functional bracing. There was a risk however, of iatrogenic nerve injury, infection and re-operation. ${ }^{13}$ Stability following internal fixation is technically demanding in the face of complex fracture patterns and osteoporosis. Non-operative management using functional bracing can be cumbersome and difficult for patients initially and has been associated with both skin problems and mal-alignment. ${ }^{4}$ Sarmiento et al. found that functional bracing in comminuted extra-articular distal humerus fractures resulted in a varus deformity averaging $9^{\circ}$ in $81 \%$ of patients with minimal loss of movement and good functional outcomes. Shoulder abduction and external rotation were commenced only when radiological and clinical evidence of fracture healing was detected. ${ }^{14}$

The objective of operative management of extra-articular metaphyseal humeral fractures is to achieve stable fixation and enable early range of movement at the elbow joint. Fracture fixation is difficult due to the restricted space for instrumentation at the distal fragment. Also, there is a need to maintain repair integrity under a large range of motion and low-to-moderate loading. It is essential to avoid impingement at the olecranon fossa. Internal fixation with dual plating systems is the gold standard for fixation. ${ }^{15}$ The majority of non-unions in extra-articular humerus fractures occur at the supracondylar level while healing of the articular components may occur in their reduced positions. Stability of the construct requires adequate bony contact with interfragmentary compression. Maximising stability between the distal fragments and the shaft of the humerus should be the focus of the fixation strategy.

Open reconstruction of extra-articular distal humerus fractures has traditionally been performed with the use of orthogonal plating. ${ }^{16}$ Meloy et al. state that implant-related complications associated with dual plating such as ulna neuritis occur in upwards of $51 \%$ of patients. Comparison of patients with $\mathrm{AO} /$ OTA 13A2 and AO/OTA 13A3 (AO/OTA - Arbeitsgemeinschaft fur Ostesynthesefragen/Orthopaedic Trauma Association) type fractures operated with a dual plating technique versus a single posterolateral contoured plate, showed comparable union rates were achieved in both groups. The single plating group had an overall better range of movement than the dual plating group, and the overall complication rate was significantly greater in the latter. ${ }^{17}$

The objective of this study was to establish by radiological and patient record analysis that the use of a single posterolateral plate for open reduction and internal fixation of extra-articular

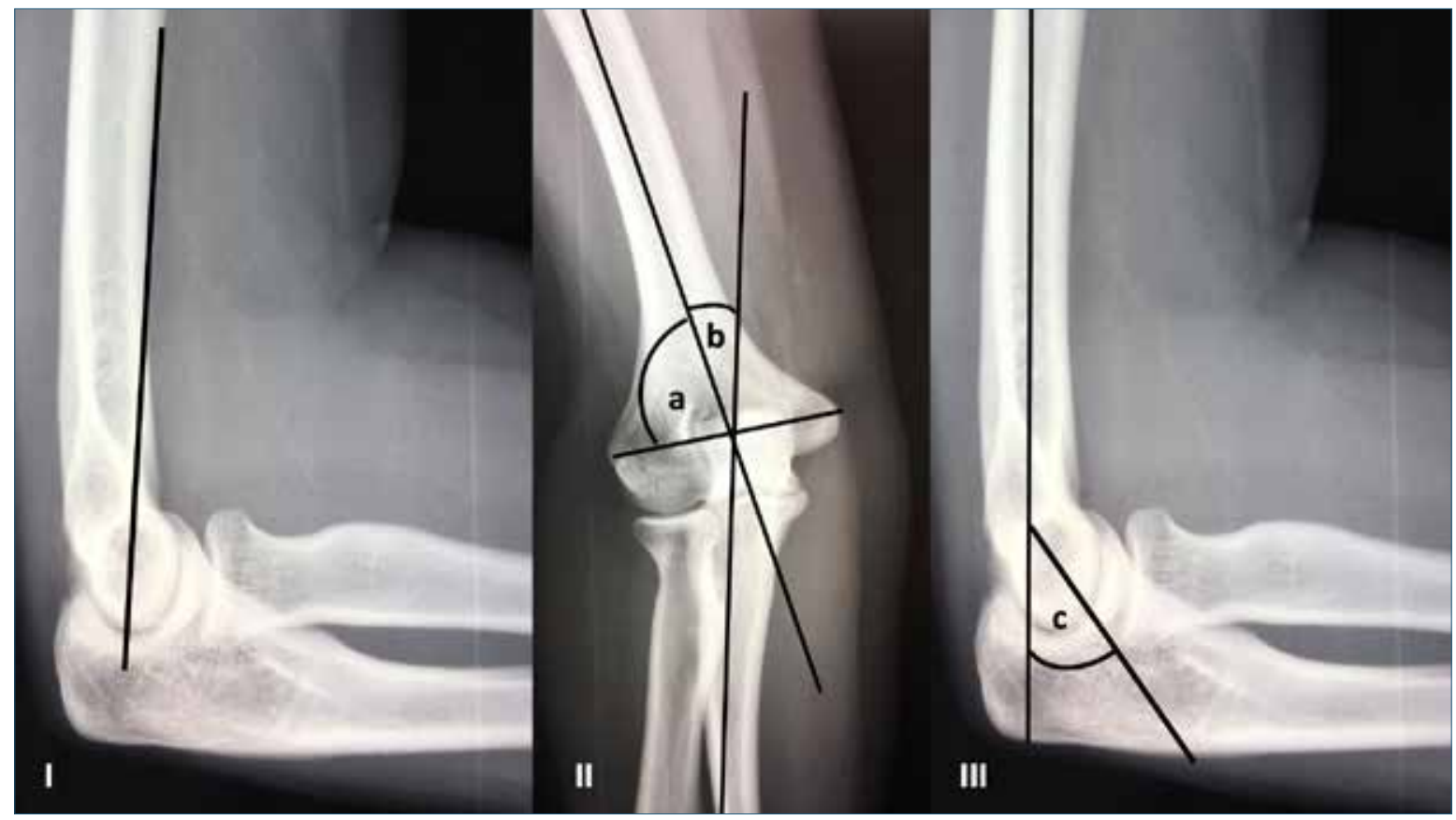

Figure 1. I) Anterior humeral line transecting capitellum; II) a: metaphyseal-diaphyseal angle, b: humero-ulnar angle; III) c: shaft-condylar angle 
metaphyseal distal humerus fractures resulted in adequate fracture healing, good functional outcomes and low complication rates.

\section{Methods}

A retrospective case review of patient records and X-rays for all patients undergoing operative intervention of extra-articular metaphyseal distal humerus fractures from 1 January 2015 to 30 November 2017 was conducted. This data was analysed using specific functional assessment criteria (QuickDASH Score), standardised radiological criteria (Figure 1) as well as listed postoperative complications as recorded in the patient's hospital records. Other parameters assessed included demographic data, data related specifically to the injury and theatre data.

\section{Patients}

Fifteen patients with extra-articular metaphyseal distal humerus fractures, AO/OTA type 13A2 and AO/OTA type 13A3 were managed surgically with a single posterolateral distal humerus locking plate. The period from 1 January 2015 to 30 November 2017 was analysed. Patient records were sourced using the

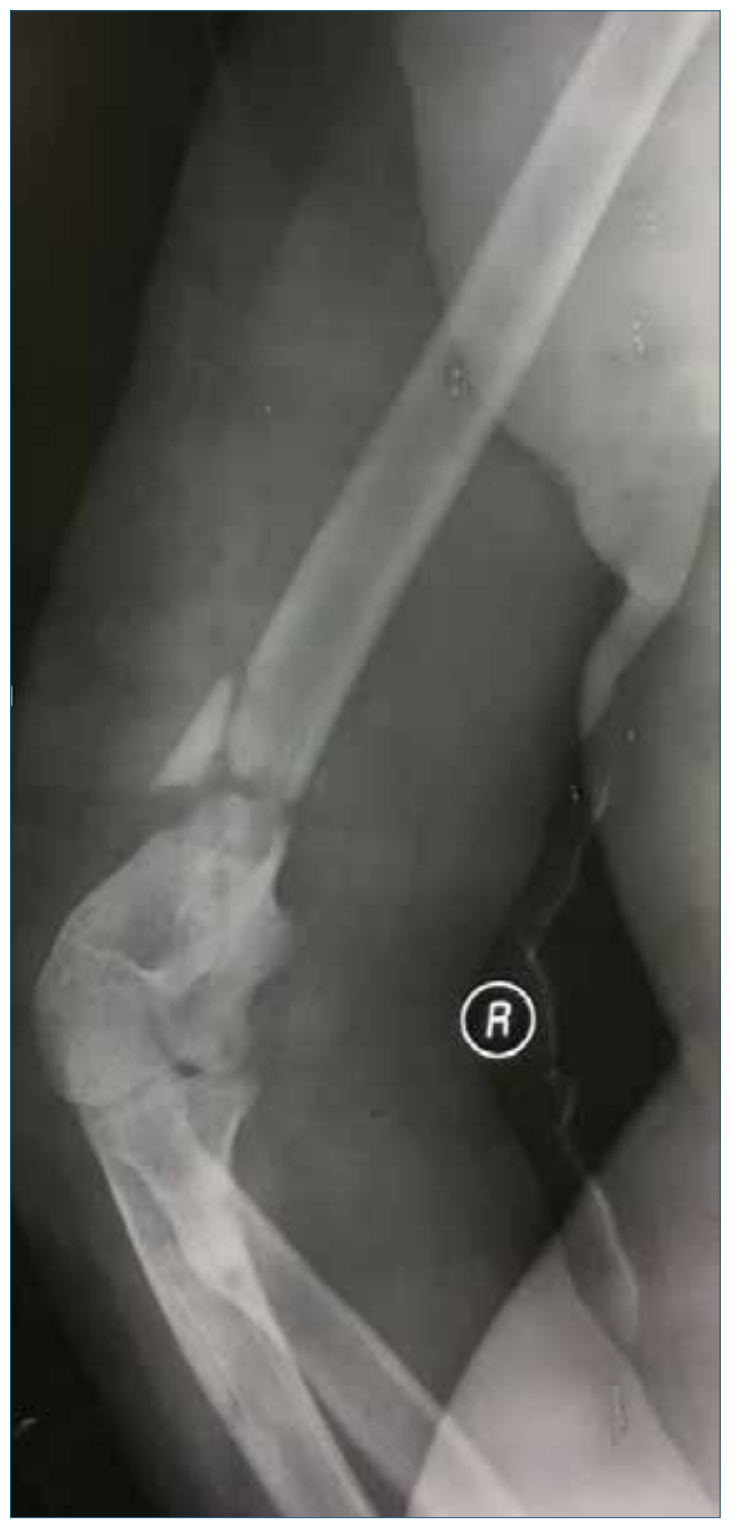

Figure 2. Pre-operative fracture $\mathrm{X}$-ray inpatient numbers from the hospital registry and archives. The outpatient files were used to trace $X$-ray films which included the pre-operative $\mathrm{X}$-ray (Figure 2) and post-operative X-rays (Figures 3 and 4).

\section{Surgical technique}

The operations were performed under general anaesthesia with the patient positioned prone with the affected arm placed over an arm support. A tourniquet was not used. A midline, posterior triceps splitting technique was used. The radial nerve was identified

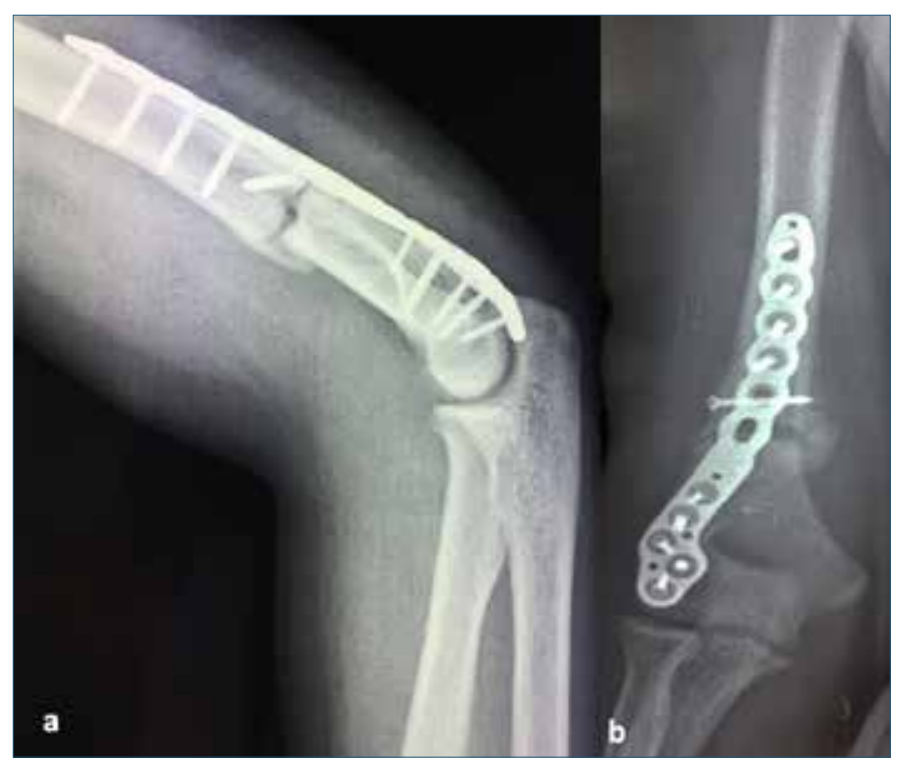

Figure 3. a) Lateral view and b) antero-posterior view (AP) at 6 weeks after posterolateral plating

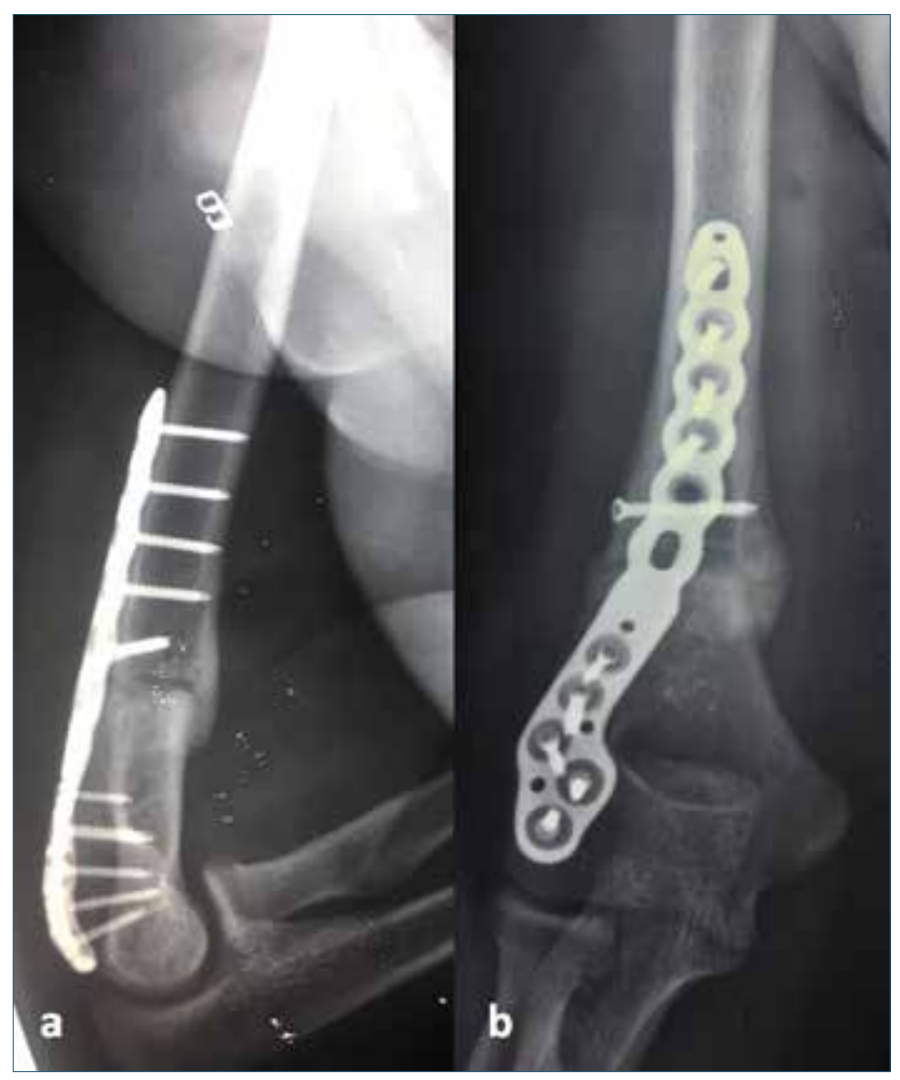

Figure 4. a) Lateral view and b) AP view at 12 weeks after posterolateral plating 


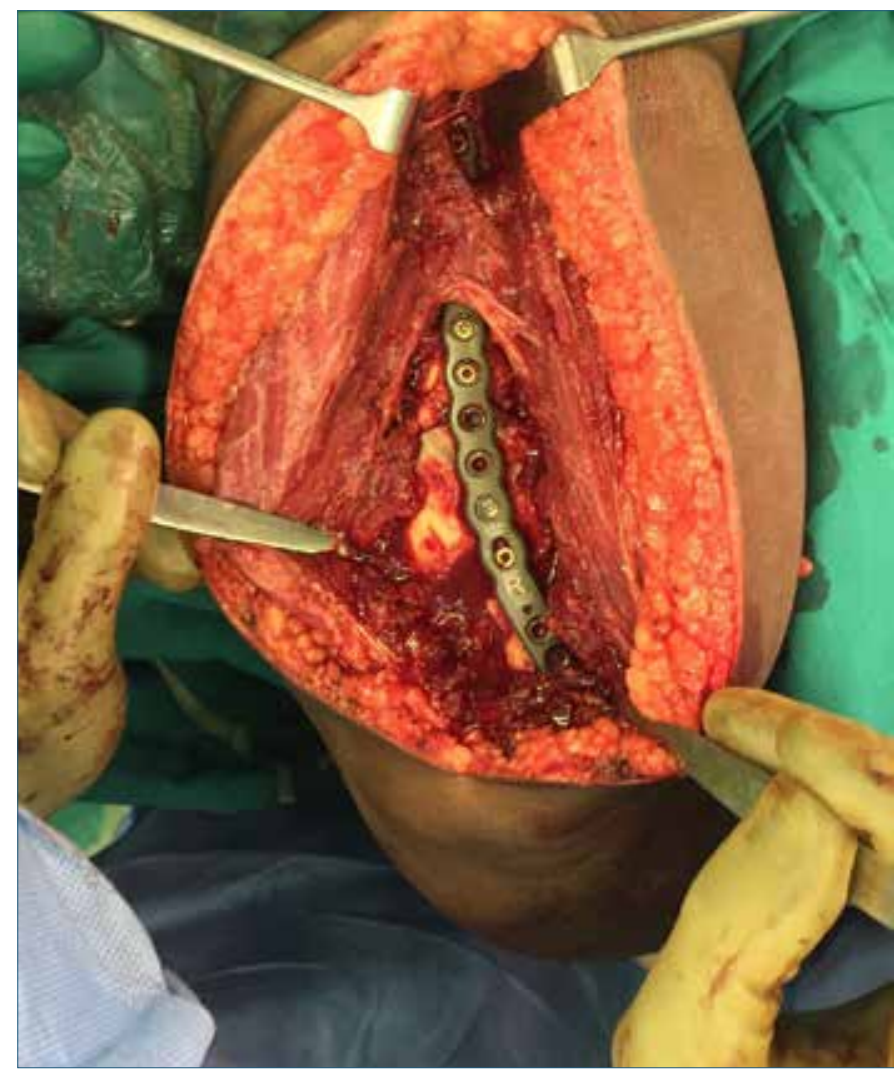

Figure 5. Intra-operative view of posterolateral plate; white arrow shows radial nerve overlying plate

and protected. Fracture fragments were manipulated and reduced under direct visualisation and temporarily fixed with K-wires. Interfragmentary screws were applied as required, following which a Stryker Variax (Michigan, USA) posterolateral distal humerus locking compression plate was used to fix the fracture (Figure 5). The plate used in all fracture fixation cases had five distal locking holes which were filled. Depending on the fracture configuration and the presence of interfragmentary screws, the metaphyseal and diaphyseal plate holes were filled accordingly. The absence of olecranon impingement was determined intra-operatively. Surgical time was documented from the time of skin incision to completion of skin closure.

\section{Post-operative care}

An above-elbow backslab and a collar and cuff were used postoperatively for 48 hours. Wound review was at 48 hours; the backslab was removed and the patient encouraged to perform active range of movement exercises. The patient was discharged home with only a collar and cuff, which the patient discarded before the next follow-up. All patients were directed to follow a home-exercise programme with physiotherapy appointments as available. Most patients had limited physiotherapy due to large patient volumes at the physiotherapy department. Skin staples were removed at 10 days post operation. X-rays were done at 6 weeks and 12 weeks post-op.

$X$-ray films were assessed by an independent reviewer, using the following parameters: ${ }^{17-19}$

1. Callus formation on three out of four cortices on anteroposterior and lateral radiographs taken 12 weeks post-operatively

2. Post-operative loss of fixation of the fracture
3. Metaphyseal-diaphyseal angle

4. Humeral-ulnar angle

5. Shaft-condylar angle

6. Percentage of the capitellum anterior to the anterior humeral line

Functional post-operative outcomes were assessed utilising a QuickDASH score calculation that was recorded in the patient's outpatient folder. Complications encountered were recorded as per post-operative record in the outpatient folder.

\section{Data analysis}

The data was analysed using the SPSS version 24 by a statistician. Descriptive statistics such as percentages were used to summarise categorical data. Measures of mean and of dispersion such as standard deviation and interquartile range were calculated for numerical variables.

\section{Results}

\section{Demographics}

Fifteen patients were included in the study - ten males and five females. The mean age of the participants was 33.13 years (range 18-52 years). Fourteen of the patients were right-hand dominant and one patient was left-hand dominant. Injuries occurred on the left side in nine cases and on the right in six cases. Mechanisms of injury included eight patients (53.3\%) involved in a motor vehicle accident (MVA), two patients who sustained gunshot wounds to the distal humerus (13.3\%), one patient with a previous distal humerus fracture non-union from a humeral nail $(6.7 \%)$, two patients who were assaulted (13.3\%) and two patients who sustained their injury after a fall (13.3\%).

\section{Functional scoring}

The mean QuickDASH score was 19.2 (range 11.4-59). The score is interpreted as 0 points for no disability and 100 points for complete disability. A QuickDASH score in a normal arm has been shown to be $7-9$ points. ${ }^{17}$ This can be interpreted as minimal impairment.

\section{Fracture union and alignment}

Fracture union was obtained in all 15 patients, with $73.33 \%$ of cases having four cortices with callus formation. Table I outlines the radiographic analysis.

\section{Surgical data}

The mean time to theatre was nine days (range 1-20 days) and the mean duration of surgery was 95.4 minutes (range 50-150 minutes) with a standard deviation of 27.8 minutes. Two patients had prolonged surgical time due to removal of metalware (patient with previous non-union and patient with a humeral nail periprosthetic fracture).

\section{Complications}

One patient developed a radial nerve palsy post-operatively with partial recovery at 12 weeks follow-up. This patient had a 10-day pre-admission delay and a 17-day inpatient delay that resulted in partial entrapment of the radial nerve in callus. 
Table I: Radiographic analysis, functional assessment and complications of cases

\begin{tabular}{|c|c|c|c|c|c|c|c|c|c|}
\hline 蒿 & $\begin{array}{l}\text { No of } \\
\text { cortices } \\
\text { with callus } \\
\text { formation }\end{array}$ & $\begin{array}{l}\text { Loss of } \\
\text { fixation }\end{array}$ & $\begin{array}{l}\text { Metaphyseal- } \\
\text { diaphyseal } \\
\text { angle } \\
\text { Normal: } \mathbf{8 2}^{\circ}-\mathbf{8 4 ^ { \circ }}\end{array}$ & $\begin{array}{l}\text { Humero-ulnar } \\
\text { angle } \\
\text { Normal: } 17.8^{\circ} \\
\text { valgus }\end{array}$ & $\begin{array}{c}\text { Shaft- } \\
\text { condylar } \\
\text { angle } \\
\text { Normal: } 40^{\circ}\end{array}$ & $\begin{array}{c}\text { Percentage } \\
\text { capitellum } \\
\text { anterior to anterior } \\
\text { humeral line } \\
\text { Normal mid-1/3 }\end{array}$ & $\begin{array}{l}\text { Quick } \\
\text { Dash } \\
\text { Score }\end{array}$ & $\begin{array}{l}\text { Duration } \\
\text { of } \\
\text { surgery }\end{array}$ & Complications \\
\hline 1 & 4 & No & 82 & 18 & 35 & $45 \%$ & 11.4 & $90 \mathrm{~min}$ & Nil \\
\hline 2 & 3 & No & 83 & 18 & 40 & $50 \%$ & 22.7 & $147 \mathrm{~min}$ & $\mathrm{Nil}$ \\
\hline 3 & 4 & No & 82 & 17 & 41 & $50 \%$ & 29.5 & $75 \min$ & Nil \\
\hline 4 & 3 & No & 87 & 19 & 36 & $55 \%$ & 11.4 & $94 \min$ & Nil \\
\hline 5 & 4 & No & 84 & 19 & 42 & $50 \%$ & 59 & $75 \mathrm{~min}$ & $\begin{array}{l}\text { Pre-op radial } \\
\text { nerve injury } \\
\text { recovered fully }\end{array}$ \\
\hline 6 & 4 & No & 81 & 16 & 40 & $45 \%$ & 13.6 & $80 \mathrm{~min}$ & Nil \\
\hline 7 & 4 & No & 87 & 19 & 40 & $50 \%$ & 11.4 & $125 \mathrm{~min}$ & Nil \\
\hline 8 & 4 & No & 85 & 19 & 42 & $50 \%$ & 13.6 & $95 \min$ & Nil \\
\hline 9 & 4 & No & 83 & 17 & 40 & $50 \%$ & 18.2 & $87 \mathrm{~min}$ & Nil \\
\hline 10 & 3 & No & 84 & 19 & 43 & $50 \%$ & 11.4 & $65 \mathrm{~min}$ & $\mathrm{Nil}$ \\
\hline 11 & 4 & No & 86 & 18 & 40 & $45 \%$ & 18.2 & $100 \min$ & $\mathrm{Nil}$ \\
\hline 12 & 4 & No & 84 & 18 & 42 & $50 \%$ & 31.8 & $150 \mathrm{~min}$ & $\begin{array}{l}\text { Intra-op radial } \\
\text { nerve injury } \\
\text { partial recovery }\end{array}$ \\
\hline 13 & 4 & No & 85 & 18 & 45 & $50 \%$ & 11.4 & $91 \mathrm{~min}$ & $\mathrm{Nil}$ \\
\hline 14 & 4 & No & 83 & 17 & 39 & $50 \%$ & 9 & $50 \mathrm{~min}$ & $\mathrm{Nil}$ \\
\hline 15 & 3 & No & 86 & 18 & 42 & $50 \%$ & 18.2 & $107 \mathrm{~min}$ & $\mathrm{Nil}$ \\
\hline
\end{tabular}

\section{Discussion}

The use of a single posterolateral locking plate for extra-articular metaphyseal distal humerus fractures resulted in adequate fracture healing, good functional outcomes and low complication rates. The treatment of these fractures is complicated by elbow stiffness, pain and limitation of function. Prolonged sick leave or incapacity leave has a negative impact on the already strained economy. In addition, it may have detrimental effects for a patient socially, psychologically and at the workplace.

Sarmiento's work favoured functional bracing of distal third humerus fractures. However, Holstein and Lewis, Reudi et al., Horne as well as Aitken and Rorabeck suggest surgical management of distal third humerus fractures as a preferable option. ${ }^{14}$ This preference followed the belief that distal humerus fractures were difficult to reduce, difficult to maintain in position, and also due to initial radial nerve palsy. Jawa et al. found that patients undergoing operative treatment fared better when compared to patients who underwent bracing. ${ }^{13}$

The objective of any treatment regimen would be to minimise the time that the patient is incapacitated with optimal stability of fracture fixation, to decrease surgical times with minimal soft tissue damage, allow early range of movement while ensuring fracture healing and low complication rates. The use of a single posterolateral locking plate is beneficial as it matches the contour of the distal humerus, does not impinge on the olecranon fossa, has increased distal fixation and it allows for a locking construct. ${ }^{11}$

O'Driscoll suggested that distal humerus fracture fixation failure begins in the lateral column. ${ }^{16}$ This is linked to the higher loading capacity of the lateral column and pseudoarthrosis usually occurring at the metaphyseal/supracondylar lateral column. ${ }^{6-8}$ The force of gravity acting on the long lever arm (the forearm), while the elbow is flexed and extended during apparently minimal use activities leads to repetitive varus stresses across the elbow.
The varus torque across the elbow results in distraction of the lateral column away from the fixation placed along the posterior surface. In the presence of cubitus varus, the mechanical axis, olecranon and the triceps line of pull are all displaced medially. The resultant repetitive external rotation torque on the ulna can stretch the lateral collateral ligament complex and lead to posterolateral rotatory instability. ${ }^{20}$ Sabalic et al. stated that distal humeral fractures have different biomechanical demands than intra-articular fractures of the distal humerus. ${ }^{15}$ Hence plates that are longer in the radial, more loaded column could at least be of equal strength to two plates. Our study supports the available literature in this regard that a single posterolateral plate provides an adequately stable construct to allow for bony union while allowing for early range of movement.

The findings of this study are similar to Meloy et al. in that their study supported the use of a single plating system, quoting improved elbow function and fewer surgical complications compared to dual plating. ${ }^{17}$ Jawa et al. found a 5\% prevalence of loosening of fixation, up to $5 \%$ prevalence of infection and up to $6 \%$ prevalence of non-union that can be expected in some operatively managed patients. Radial nerve injury has a prevalence of $3 \%{ }^{13}$ There was no loss of fixation post-operatively in our study, with no cases of infection or non-union.

The average duration of surgery for single plating with a locking compression technique in 47 patients assessed by Chavan et al. was $94 \pm 10$ min. ${ }^{21}$ Reising et al. quote the mean time of operation for fractures with articular involvement as 215 minutes (range: 77-405 minutes) with Soon et al. quoting a mean value of 150.3 minutes (range: 70-240 minutes).22,23 A shortened duration of surgery combined with less soft tissue dissection during the procedure would theoretically decrease the number of implantrelated problems post-operatively. ${ }^{16}$ This study fulfils both these objectives. There is a significantly higher density of vessels in cancellous bone of the epicondylar area than in the watershed 
area (trochlear, olecranon fossa and coronoid fossa). ${ }^{24}$ The use of a single posterolateral plate respects this finding as it minimises soft tissue stripping and hence the blood supply in the epicondylar area in comparison to the dual plating technique.

In a biomechanical comparison of three standard fixation constructs, Scolaro et al. compared a single posterolateral plate, $3.5 \mathrm{~mm}$ locking compression plate (LCP) and dual plating for extra-articular distal humerus fractures conducted on saw bones. ${ }^{11}$ They found that the single posterolateral plating fixation had significantly greater bending stiffness, torsional stiffness and yield strength than a single non-contoured LCP construct in more proximal fractures. In more distal fractures dual plating was biomechanically superior. Limitations of this comparison is that the study was conducted on saw bones and not cadaveric bones, and the fracture configuration may not be the same as in a clinical setting. Overall more comparative studies are needed to validate this finding.

There are limitations to this study. In this retrospective analysis, the total patient number is small. Due to the rare occurrence of this particular subset of fractures it would take a prolonged period to obtain a larger patient number. A direct comparison of operating times, functional outcomes, radiographic outcomes and complications in patients with this group of fractures with dual plating versus single posterolateral plating would be preferable.

\section{Conclusion}

Stabilisation and fixation of extra-articular articular distal humerus fractures have been traditionally conducted with dual plating techniques with a sizeable post-operative complication rate, extensive soft tissue dissection and varying functional outcomes. Our study reveals that the use of a single posterolateral plate provides adequate stability of fracture fixation, good functional outcomes and low complication rates. With shorter surgical time duration and less soft tissue dissection, this type of fixation provides a valid alternative to the previous dual plating techniques. The study supports current literature validating the use of a single posterolateral plating system in this subset of fractures. However, future studies that compare dual plating directly to single posterolateral plating for these fractures would provide further insight.

\section{Ethics statement}

Institutional Review Board (IRB) ethical approval was obtained from the University of KwaZulu-Natal Biomedical Research Ethics Committee via an expedited application referenced as: BE587/17 prior to commencement of the study. The study was conducted according to the ethical principles for medical research on human subjects as defined by the World Medical Association Declaration of Helsinki (amended at the MA General Assembly, Seoul, Oct 2008). For this study, formal consent was not required due to the study design being a retrospective chart review.

\section{References}

1. Norman R, Matzopoulos R, Groenewald P, Bradshaw D. The high burden of injuries in South Africa. Bulletin of the World Health Organisation. 2007;85(9):649-732. http://www.who.int/bulletin/ volumes/85/9/06-037184/en/

2. Eastwood WJ. The t-shaped fracture of the lower end of the humerus. J Bone Joint Surg. 1937;19:364-69.

3. Tejwani NC, Murthy A, Park J, McLaurin TM, Egol KA, Kummer FJ. Fixation of extra-articular distal humerus fractures using one locking plate versus two reconstruction plates: a laboratory study. J Trauma 2009;66(3):795-99. doi:10.1097/ TA.0b01e318181e53c
4. Lokesh CR, Vishwanath $Y$, Srinivas N, Girish HR. Management of distal diaphysio-metaphyseal junction humerus fractures with single column posterolateral LCP - our results. Journal of Evolution of Medical and Dental Sciences 2015;4(20):3427-32. doi: 10.14260/jemds/2015/495

5. Goel DP, Pike JM, Athwal GS. Open reduction and internal fixation of distal humerus fractures. Operative Techniques in Orthopaedics. 2010;20:24-33.

6. Penzkofer R, Hungerer S, Wipf F, von Oldenburg G, Augat P. Anatomical plate configuration affects mechanical performance in distal humerus fractures. Clin Biomech 2010;25(10):972-78.

7. Windolf M, Maza ER, Gueorguiev B, Braunstein V, Schweiger $K$. Treatment of distal humerus fractures using conventional implants. Biomechanical evaluation of a new implant configuration. BMC Musculoskelet Discord. 2010;11:172. https:// doi.org/10.1186/1471-2474-11-172

8. Halls AA, Travill A. Transmission of pressures across the elbow joint. Anat Rec. 1964;150:243-47.

9. Shah JJ, Bhatti NA. Radial nerve paralysis associated with fractures of the humerus. A review of 62 cases. Clin Orthop Relat Res. 1983 Jan-Feb;172:171-76.

10. Yam A, Tan TC, Lim BH. Intraoperative interfragmentary radial nerve compression in a medially plated humeral shaft fracture: a case report. J Orthop Trauma. 2005 Aug;19(7):401-93.

11. Scolaro J, Matzon JL, Mehta S. Tips and tricks - surgical fixation of extra-articular distal humerus fractures with a posterolateral locking compression plate (LCP). University of Pennsylvannia Orthopaedic Journal. 2009;19:120-25.

12. Gerwin M, Hotchkiss RN, Weiland AJ. Alternative operative exposures of the posterior aspect of the humeral diaphysis with reference to the radial nerve. J Bone Joint Surg Am. 1996 Nov;78(11):1690-95.

13. Jawa A, McCarty P, Doornberg J, Harris M, Ring D. Extra-articular distal third diaphyseal fractures of the humerus. A comparison of functional bracing and plate fixation. Journal of Bone and Joint Surg Am. 2006 Nov;88(11):2343-47. doi:10.2106/JBJS.F.00334

14. Sarmiento A, Horowitch A, Aboulafia A, Vangsness CT Jr. Functional bracing for comminuted extra-articular fractures of the distal third of the humerus. Journal of Bone and Joint Surgery (Br). 1990;72(2):283-87.

15. Sabalic S, Kodvanj J, Jecic S. The position of the implant for extraarticular fractures of the distal humerus - the new hypotheses for management. Rad 521. Tehnicke znanosti knj. 2015;17:65-76. http://hrcak.srce.hr/141370

16. O'Driscoll SW. Optimizing stability in distal humerus fractures. Journal of Elbow and Joint Surgery. 2005;14(1). Supp: S186-S194.

17. Meloy GM, Mormino MA, Siska PA, Tarkin IS. A paradigm shift in the surgical reconstruction of extra-articular distal humeral fractures: single column plating. Injury. 2013;44:1620-24.

18. Capo T, Debkowska MP, Liporace F, Beutel BG, Melamed E. Outcomes of distal humerus diaphyseal injuries fixed with a single column anatomic plate. International Orthopaedics (SICOT). 2014;38:1037-43

19. Yang $Q$, et al. Surgical treatment of adult extra-articular distal humeral diaphyseal fractures using an oblique metaphyseal locking compression plate via a posterior approach. Medical Principles and Practice, 2012;32:40-45. doi: 10.1159/000331791

20. O’Driscoll SW, Spinner RJ, McKee MD. Tardy posterolateral rotatory instability of the elbow due to cubitus varus. 2001. J Bone Joint Surg Am. 2001 Sep;83-A(9):1358-69.

21. Chavan UC, Mahesh SG, Gudda LN, Qureshi F. Treatment of distal humerus fractures with extra-articular locking compression plate technique. International Journal of Surgery and Medicine. 2017;3(2):103-106.

22. Reising K, Hauschild O, Strohm PC, Suedkamp NP. Stabilization of articular fractures of the distal humerus: Early experience with a novel perpendicular plate system. Injury. 2009;40:611-17. doi :10.1016/j.injury.2008.12.018

23. Soon JL, Chan BK, Low CO. Surgical fixation of intra-articular fractures of the distal humerus in adults. Injury. 2004;35:44-54.

24. Wegmann K, Burkhart KJ, Koslowsky TC, Koebke J, Weiss WF, Muller LP. Arterial supply of the distal humerus. Surg Radiol Anat. 2014 Sept;36(7):705-11. 